\title{
Dexamethasone as endocrine disruptor; type I and type II (anti) oestrogenic actions on the ovary and uterus of adult Wistar rats (Rattus Novergicus)
}

\author{
Joseph Babatunde Dare ${ }^{1}$, Babajide Arogundade ${ }^{1}$, Olakunle Oladipupo Awoniyi ${ }^{1}$, Adebiyi Aderinola Adegoke ${ }^{1}$, \\ Damilare Adedayo Adekomi ${ }^{1}$ \\ ${ }^{1}$ Anatomy Department, Faculty of Basic Medical Sciences, College of Health Sciences, Osun State University, \\ Osogbo, Nigeria
}

\begin{abstract}
Objective: Dexamethasone is a widely used glucocorticoid, which has been prescribed increasingly in recent years. The effects of Dexamethasone on the ovary and uterus was investigated in present study.

Methods: Twenty (20) adult female Wistar rats, weighing 130-170 g were assigned to four (4) groups of five (5) animals each. The rats in the control group received saline, while the rats in the experimental group was subjected to oral treatment of dexamethasone of $12 \mathrm{mg} / \mathrm{kg}, 10 \mathrm{mg} / \mathrm{kg}$, and $7 \mathrm{mg} / \mathrm{kg}$ doses daily for a period of 10 days, respectively. The rats were slaughtered after 24 hours of the last administration, and the uterus and ovaries were harvested following abdominal incision. Histological and biochemical investigations were carried out and the results were analyzed using ANOVA with the Graph-Pad prism software package 6.

Results: There was a significant decrease in the activities of the carbohydrate metabolic enzymes of the uterus in the dexamethasone-treated groups compared to the control group $(p<0.05)$. Vacuolation, atrophy, thick epithelium, enlarged cells, inactive interstitial glands and follicular cyst, characterized the histological observation in the dexamethasone-treated groups in a dose-dependent manner.

Conclusion: This present study revealed that highdose dexamethasone causes multiple changes in the histological features of the ovary and uterus, exerting type I and type II anti-oestrogenic effects on the female reproductive compartment.
\end{abstract}

Keywords: dexamethasone, ovary, uterus, anti-oestrogenic, endocrine disruptors and stress

\section{INTRODUCTION}

The female reproductive system consists of three major components, the ovary, uterine tube and uterus, which function synchronously under strict hormonal control, in a graded continuum, from fully competent menstrual cycles (eumenorrhoea) to the complete absence of cyclic ovarian activity (amenorrhea) (Agarwal et al., 2005; Tsigos \& Chrousos, 1994). Psychological stressors affect the reproductive axis, causing it to depart from eumenorrhoea and move towards amenorrhea (Bloom et al., 2001; Inoue et al., 2003; Klein et al., 2001). Studies have confirmed the existence of reproductive suppression mechanisms on the hormonal pathways, through which several isolated, intense stressors impact the reproductive function (Sugama \& Conti, 2008; Tarín, 1996; Brady et al., 2016). However, the mechanisms through which stress suppresses reproduction in humans are the major focus of current research (Cymerman \& Rock, 1994).
Glucocorticoids (GCs) classified as corticosteroids are an example of steroid hormones. Glucocorticoids bind to a receptor called glucocorticoid receptor (GR) (Pelt, 2011). These receptors are present in vertebrate animal cells. Glucocorticoids (glucose + cortex + steroid) regulate glucose metabolism, and it is synthetized in the adrenal cortex (Chrousos et al., 1993). It is also known that glucocorticosteroids form part of the feedback mechanism in the immune system, suppressing the immune function, consequently leading to inflammation. GCs are used in medicine to treat diseases caused by an overactive immune system, such as allergies, asthma, autoimmune diseases, and sepsis (Liu et al., 2010; 2011). GCs have many diverse (pleiotropic) effects, including potentially harmful side effects (Matsuwaki, 2004). GCs have been reported to interfere with abnormal cell division that take place in the cancer cell formation mechanism; therefore high doses of GCs are used in the treatment of cancer (Pelt, 2011). This includes inhibitory effects on lymphocyte proliferation, as in the treatment of lymphomas and leukemia; and the mitigation of side effects of anticancer drugs (Provan et al., 2010).

GCs bind to the glucocorticoid receptor (GR), and activate the GR complex, which in turn, up-regulates the expression of anti-inflammatory proteins in the nucleus, and reduces the expression of pro inflammatory proteins in the cytosol by preventing the translocation of other transcription factors from the cytosol into the nucleus (trans-repression) (Koch et al., 2000, Leung \& Bloom, 2003). Glucocorticoid specific receptors, target cells, and effects distinguished GCs from mineralocorticoids and sex steroids. However, corticosteroid includes both glucocorticoids and mineralocorticoids (produced by the adrenal cortex). Glucocorticoids are secreted in the zona fasciculata of the adrenal cortex, whereas mineralocorticoids are synthesized in the zona glomerulosa (Sugino et al., 2004). Cortisol, also known as hydrocortisone, is the most important human glucocorticoid ever known. It is essential for survival, and it regulates or supports cardiovascular, metabolic, immunologic, and homeostatic functions. It is worth of note that various synthetic glucocorticoids are available; these are used either as replacement therapy in glucocorticoid deficiency or to suppress the immune system (Lupien et al., 2009).

Dexamethasone is part of the synthetic glucocorticoid that suppresses the immune system, being 20-30 times stronger than hydrocortisone. It binds more tightly to the glucocorticoid receptor than cortisol does (Gao et al., 2003; Carlson, 2010). Glucocorticoid therapy is often limited by several adverse reactions associated with GC excess. Excess GC results in growth retardation in children; immunosuppression; cardiovascular disorders like hypertension and atherosclerosis; osteoporosis; myopathy; and diabetes mellitus. Currently, attention is focused on oxidative stress as one of the major determinants of endothelial 
dysfunction and cardiovascular senescence. The main reason for all unwanted effects of GC is that dexamethasone induces the overproduction of reactive oxygen species, causing unbalance of physiological processes (Matsuwaki et al., 2004).

Studies have shown that the response to stress is usually accompanied by the hyperactivation of the hypothalamic-pituitary-adrenal (HPA) axis. Female hypothalamus contains higher concentration of corticotrophin-releasing hormone $(\mathrm{CRH})$ than their male counterpart; therefore, the HPA axis reaction to stress is higher in females than in males. Stress is a potent activator of $\mathrm{CRH}$ release from the hypothalamus and extra-hypothalamic sites (Pazirandeh et al., 2002). CRH type-I receptor knockout mice have shown a deficient ability to mount an effective stress response. A direct neural connection exists between $\mathrm{CRH}$ and $\mathrm{GnRH}$; $\mathrm{CRH}$ is the major regulator of the HPA axis and the CRH-induced proopiomelanocortin peptide, such as $\beta$-endorphin, reduces the hypothalamic $\mathrm{GnRH}$ pulse generator and concurrently inhibits GnRH secretion. The decrease in pulsatile release of $\mathrm{LH}$ subsequently leads to anovulation and interruption of endometrial decasualization and pregnancy wastage (Mazerbourg et al., 2003). Dexamethasone, as a corticosteroid, is used in the treatment of rheumatic problems, a number of skin diseases, severe allergies, asthma, chronic obstructive lung disease and brain swelling (Leung et al., 1997). Therefore, the study aimed at investigating the impact of dexamethasone on the ovary and uterus of adult Wistar rats.

\section{MATERIALS AND METHODS}

\section{Animal Care and Management}

Twenty (20) adult Female Wistar rats, weighing 130$170 \mathrm{~g}$ were procured from the College of Health Sciences Animal House, Osun State University, Osogbo. The ethical approval on animal act right was obtained from the Institutional Animal Care Committee of the same Institution. The animals were randomly divided into four (4) groups with each group comprising of five $(n=5)$ rats. They were kept in the Laboratory for two (2) weeks for acclimatization and were fed on a standard diet (Vital Feeds and Grand Cereals Ltd); water was given ad libitum and maintained under standard conditions. The animal room was well ventilated with a temperature range of $25-27^{\circ} \mathrm{C}$ under day/night in a 12-12 h photoperiodicity. All the experimental procedures were done following the experimental guidelines of the Institutional Animal Ethics Committee (IAEC) of the Osun State University, Osogbo campus, Osun State.

\section{Administration}

Twenty (20) rats with an average weight of $130 \mathrm{~g}$ were used in this experiment and were subdivided into 4 groups $1,2,3$, and 4, of five (5) animals. The animals in group 1 received only distilled water and were tagged the control group. Those in groups 2, 3, and 4 received different doses of dexamethasone. Freshly prepared dosages of dexamethasone were administered each day of the experiment, by dissolving $30 \mathrm{mg}$ of dexamethasone in $50 \mathrm{ml}$ of distilled water. The animals in group 2 received $12 \mathrm{mg} / \mathrm{kg} /$ body weight of dexamethasone (DEX). Groups 3 and group 4 received $10 \mathrm{mg} / \mathrm{kg}$ and $7 \mathrm{mg} / \mathrm{kg} /$ body weight respectively of dexamethasone (DEX). The drug was administered orally, using a metal oral cannula. The treatment lasted for seven (7) days and was carried out at 07:00 hours daily.

\section{Animal slaughtering}

The animals were euthanized 24 hours after the last administration. Their uteruses and ovaries were excised following an abdominal incision, and were later fixed in Bouin's fluid for histological analysis using H/E and PAS stains. The uterus was also homogenized in $5 \%$ sucrose solution in cold ice for determining the Glucose-6-phosphate dehydrogenase (G-6-PDH) activity in Tissue Homogenate using the method of Charmandari et al. (2008).

\section{Histological Techniques}

Histological examination was carried out on the tissues fixed in Bouin's fluid. Tissue blocks were sectioned for routine Hematoxylin and Eosin (H\&E). The fixed organs were cut in slabs of about $0.5 \mathrm{~cm}$ thick transversely and transferred to $70 \%$ alcohol for dehydration. The tissues were passed through $90 \%$ and absolute alcohol and xylene for different durations before they were transferred into two changes of molten paraffin wax for 1 hour each in an oven at $65^{\circ} \mathrm{C}$ for infiltration. They were subsequently embedded and serial sections using a rotary microtome at six microns $(6 \mu)$. The tissues were transferred onto albumenized slides and allowed to dry on a hot plate for 2 minutes. The slides were dewaxed with xylene and passed through absolute alcohol ( 2 changes); $70 \%$ alcohol, 50\% alcohol and then to water for 5 minutes. The slides were then stained with hematoxylin and eosin.

\section{Statistical Analysis}

The results were expressed as Mean \pm standard error of mean (SEM), and subjected to statistical analysis using the ANOVA Graph-Pad prism software package 6 for data analysis.

\section{RESULTS}

Significant reduction in animal bodyweight was noticed across the groups. However, the animals treated with $12 \mathrm{mg} / \mathrm{kg}$ body weight demonstrated higher reduction in their weight when compared to their control counterparts' $p<0.01$. Reduction in bodyweight was dose-dependent, as shown in the Figure 1 below. Figure 2 demonstrates G-6$\mathrm{PDH}$ enzyme activity following treatment with different doses of dexamethasone-exogenous substances, at low doses, G-6-PDH enzymes' activities were reduced as the concentration of the enzymes were lower in the uteruses of the treated animals. Therefore, dexamethasone exerts reduction effects on carbohydrate metabolism enzymes even at lower doses. This reduction in G-6-PDH enzyme activity was more pronounced and significant at lower doses than at higher doses.

The histological observation of the uterus of the control animals demonstrated tall columnar cells lining the endometrium. The endometrium classically revealed the brush border and the tall columnar epithelium lining, the inner layer of the endometrium. The endometrium's two functional layers, the luminal stratum and the basal stratum basalis were demonstrated on Plate 1 . However, the uterine sessions of rats treated with $7 \mathrm{mg} / \mathrm{kg} /$ body weight of dexamethasone showed thickened luminal and/ glandular epithelium with increased number of enlarged cells. Thin, atrophic endometrial and glandular epithelium consisting of low columnar cells, with sparse endometrial glands and atrophic myometrium, which are characteristic manifestation of type I anti-oestrogenic effects of endocrine disruptors' (Plate 2).

The uterine sections of the rats treated with 10 and 12 $\mathrm{mg} / \mathrm{kg} /$ body weight of dexamethasone revealed thickened luminal and/glandular epithelium with increased number of enlarged cells, attenuated, low columnar luminal and glandular epithelium and sparse endometrial glands and atrophic myometrium, hyperplasia and hypertrophy of luminal and glandular epithelium, and cystic endometrial glands. In the animals treated with $12 \mathrm{mg} / \mathrm{kg} /$ body weight 
body weight gain

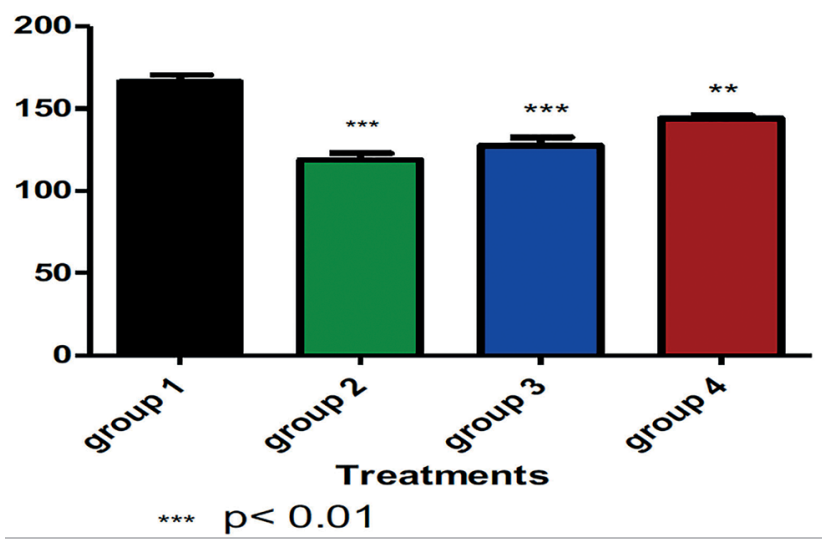

Figure 1. The average animal body weight gain in each group. G-6-PD enzyme activity was significantly reduced in the animals that were treated with dexamethasone. It was observed that rats treated with $12 \mathrm{mg} / \mathrm{kg} /$ body weight of dexamethasone demonstrated higher significant reduced G-6-PD enzyme activities relative to the control and rats treated with $10 \mathrm{mg} / \mathrm{kg}$ and $7 \mathrm{mg} /$ $\mathrm{kg} /$ body weight of dexamethasone as shown in Figure 2.

of dexamethasone dilation/cystic change in endometrial glands, neutrophil infiltration of endometrium, transformation of luminal/glandular columnar epithelium into a stratified squamous epithelium and squamous metaplasia present in luminal and glandular epithelium were well-expressed, these are observable features that classified type II anti-oestrogenic effects on the uteruses' (Plates 3 and 4).

Ovarian histopathological observation showed at 10 and $12 \mathrm{mg} / \mathrm{kg} /$ body weight of dexamethasone atrophy inactive interstitial gland and interstitial stromal cell hypertrophy/hyperplasia, reduced numbers of Follicles and corpora luteal and follicular cysts accompanied by pathological changes or histological alterations observed in the uterine compartment as depicted on Plates 5 and 6.

\section{DISCUSSION}

This study has demonstrated a decrease in bodyweight and G-6-PDH enzyme activities by the administration of dexamethasone in a dose-dependent manner, with the highest significant reduction observed at $12 \mathrm{mg} /$ $\mathrm{kg}(p<0.05)$. The studies by Rhen \& Cidlowski (2005) and Revollo \& Cidlowski (2009) indicated that dexamethasone changes the glucocorticoid stimulant and reactive gene expression in the nuclei of ovarian cells under the regulation of glucocorticoid. Song et al. (2011) studied the effects of dexamethasone on Bax protein expression as an apoptotic protein in the germ cells of 35 female mice, and found that glucocorticoid compounds such as dexamethasone can come up with apoptosis and disruption in oogenesis processes affecting pro-apoptosis proteins such as Bax. And, in this study, dexamethasone has led to damage to uterine tissue. In the present study, the administration of Dexamethasone resulted in atrophy and inactive interstitial glands, reduced numbers of Follicles and corpora luteal, follicular cysts and the histological profile of the uteruses showed dilation/cystic changes in endometrial glands, transformation of luminal/glandular columnar epithelium into a stratified squamous epithelium.

As expressed in type I anti-oestrogenic morphological responses associated with endocrine disruption, thin, atrophic endometrial and glandular epithelium consisting of low columnar cells and sparse endometrial glands and

\section{G-6-PDH METABOLISM}

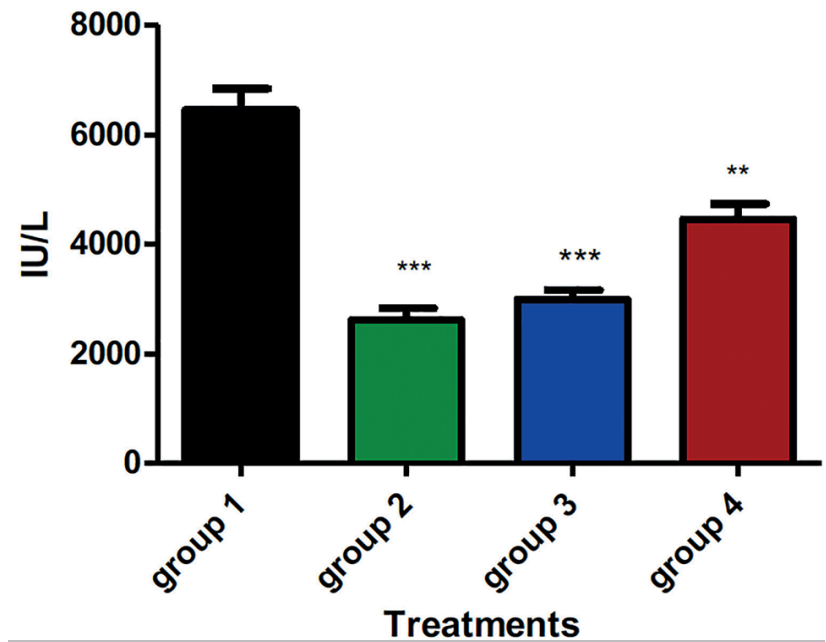

Figure 2. The result obtained shows a decrease in the activities of the action of carbohydrate metabolic enzymes of the uterus in the groups treated with dexamethason.

atrophic myometrium (Yuan, 1991; Goldman et al., 2000) as well as in the ovary, endocrine disruption cause atrophy with inactive interstitial glands; glandular cells are small and spindle-shaped and associated cystic anovulatory follicle present.

This study has expressed parallel observations among the animals that were administered with dexamethasone even in a dose-dependent manner. Therefore, in line with the medications of the histological actions of endocrine disruptors, as described by Yuan (1991), dexamethasone could be classified as an endocrine disruptor, producing type I anti-oestrogenic effects on the ovary and uterus of animal models. Probable reasons could be attributed to aromatase inhibition, which impairs the conversion of androgens (produced by theca interna cells) to estrogen by the follicular zona granulosa. Endogenous production of ovarian estrogen is thus reduced, initiating widespread atrophic reproductive tract changes. Modulation of feedback control on the hypothalamus and pituitary by reduced endogenous estrogen levels suppress gonadotrophin secretion, resulting in the formation of follicular cysts from anovulatory follicles (Yuan, 1991; Li \& Davies, 2007). This type I anti-oestrogenic effect was clearly expressed in the ovaries and uteruses of the animals treated with $7 \mathrm{mg} /$ $\mathrm{kg} /$ body weight of dexamethasone as shown on Plates 2 and 7.

Dexamethasone also caused degeneration in follicles, with oocyte death and ovarian cortex vacuolation. Reduction in the number of follicles and corpora luteal, which characterizes ovarian atrophy, were observed in the animals treated with $10 \mathrm{mg} / \mathrm{kg}$ and $12 \mathrm{mg} / \mathrm{kg} /$ body weight of dexamethasone. Hyperplasia and hypertrophy of luminal and glandular epithelium of the uterus was noticed in animals treated with higher doses of dexamethasone.

These observations characterized the type II anti-oestrogenic effect, as revealed by Yuan (1991) and Li \& Davies (2007). The administration of dexamethasone may result in negative feedback at the hypothalamic-pituitary-gonadal axis, inhibiting gonadotrophin release, consequently inducing ovarian atrophy and hyperplasia in the lining columnar and glandular epithelia, as per shown on Plates 4 and 6. Pazirandeh et al. (2002) stated that corticotrophin releasing hormones $(\mathrm{CRH})$, the major regulator of the HPA 

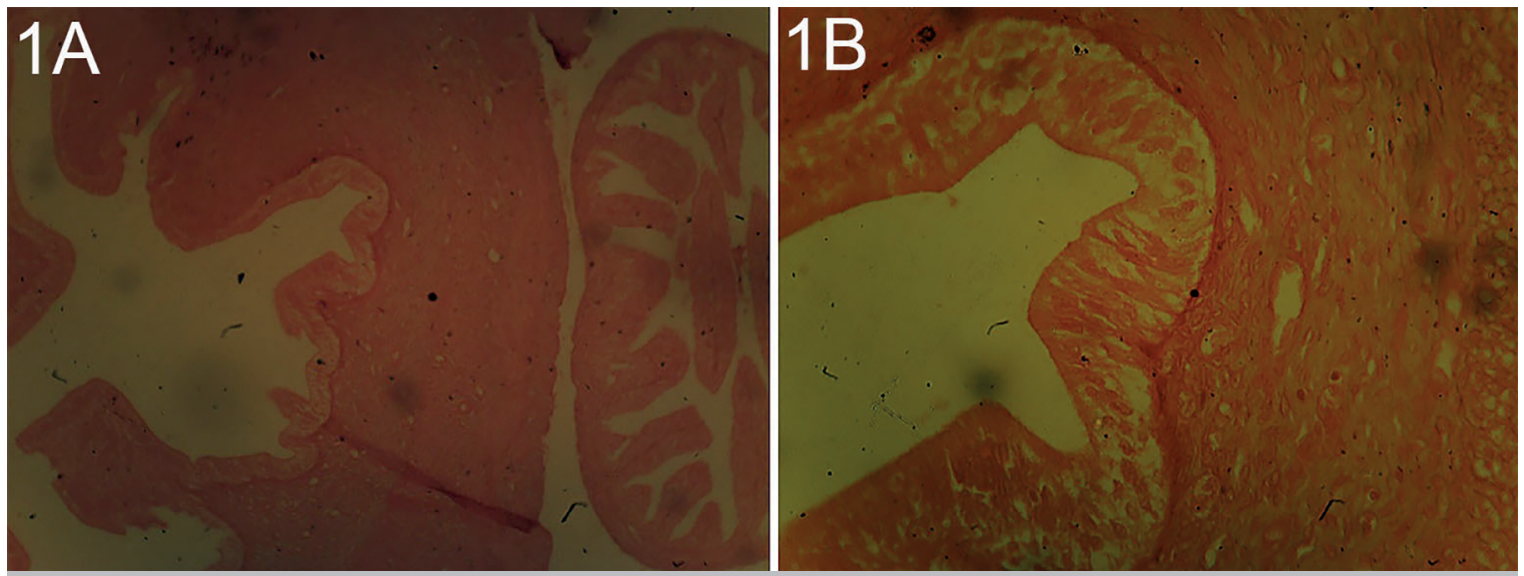

Plates 1 A and B. Uterine session of a rat from the control group stain with H/E X 100 and $X 400$. The three (3) layers of the endometrium, myometrium and perimetrium were distinct. Characterized with tall columnar cells at the epithelia lining, showing the basic features of the uterus; the two distinct layers of endometrium and myometrium. The endometrium classically revealed the brush border and the tall columnar epithelium lining the inner layer of endometrium. The endometrium two functional layers, the luminal stratum and the basal stratum basalis were shown.
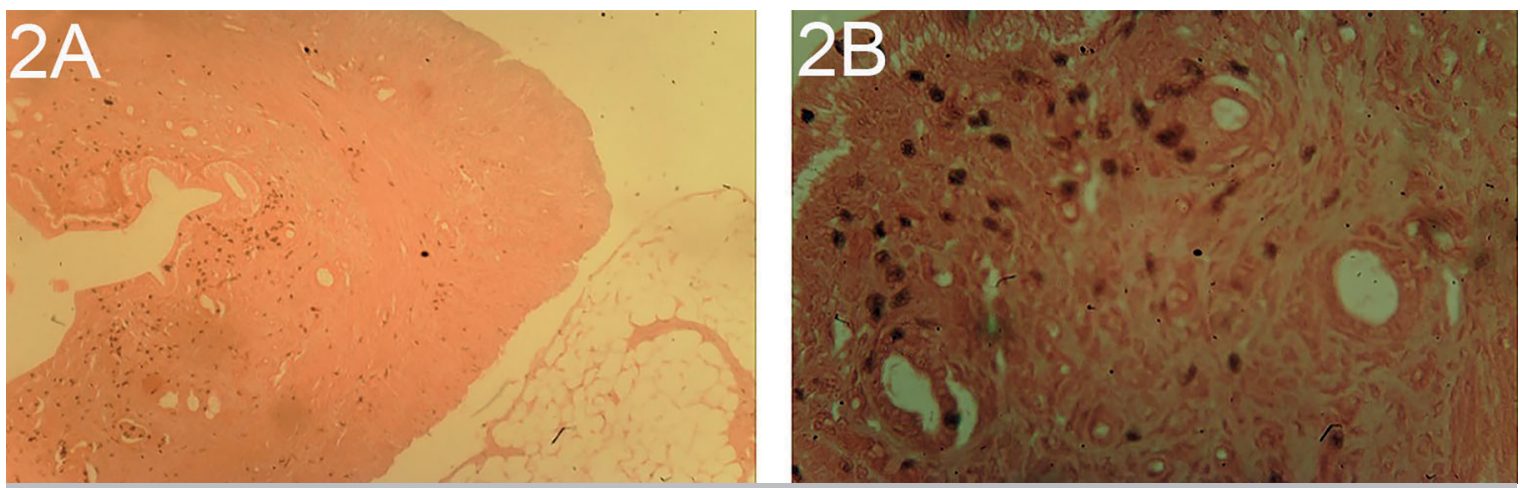

Plates 2 A and B. Uterine session of rat treated with $7 \mathrm{mg} / \mathrm{kg} /$ body weight of dexamethasone stain with H/E X100 and X400 shows thickened luminal and glandular epithelium with increased number of enlarged cells. Thin, atrophic endometrial and glandular epithelium consisting of low columnar cells. Sparse endometrial glands and atrophic myometrium.
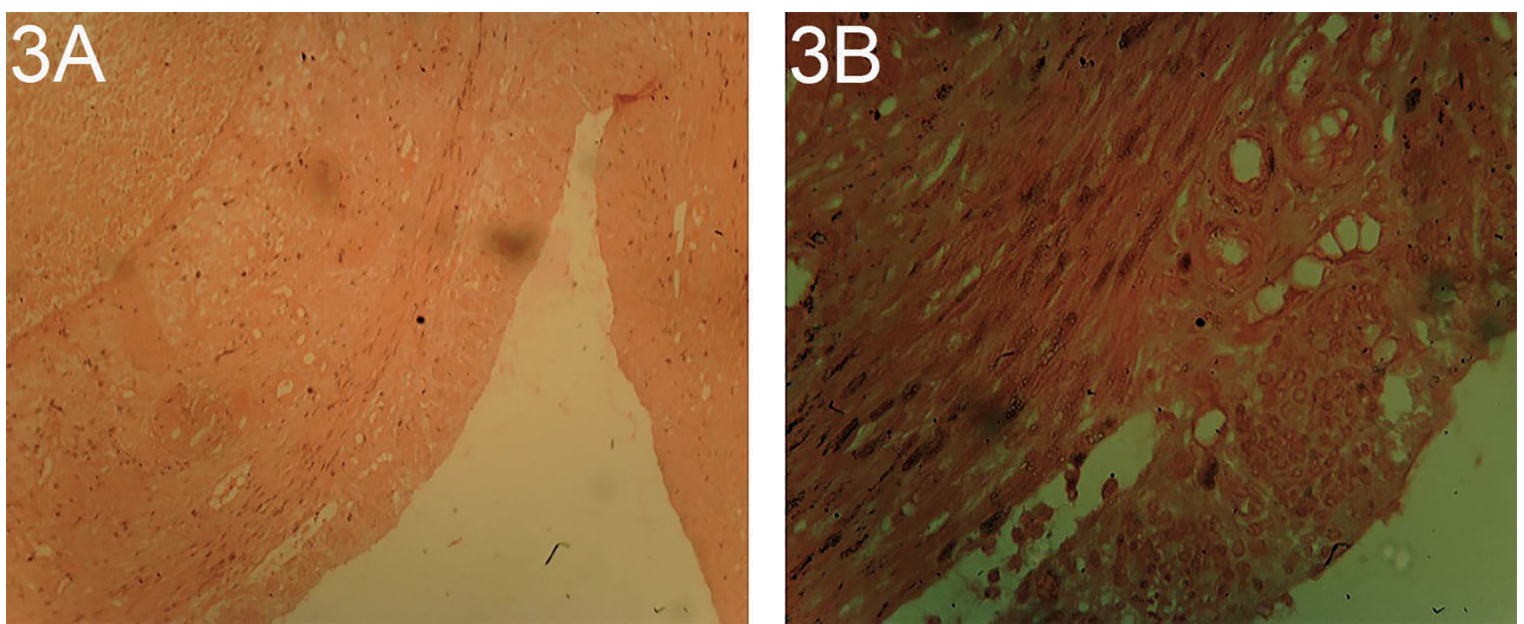

Plates 3 A and B. Uterine section of rats treated with $10 \mathrm{mg} / \mathrm{kg} / \mathrm{body}$ weight of dexamethasone stain with H/E X100 and X400 shows thickened luminal and glandular epithelium with increased number of enlarged cells, attenuated, low columnar luminal and glandular epithelium and sparse endometrial glands, atrophic myometrium, hyperplasia, hypertrophy of luminal and glandular epithelium with cystic endometrial glands. 

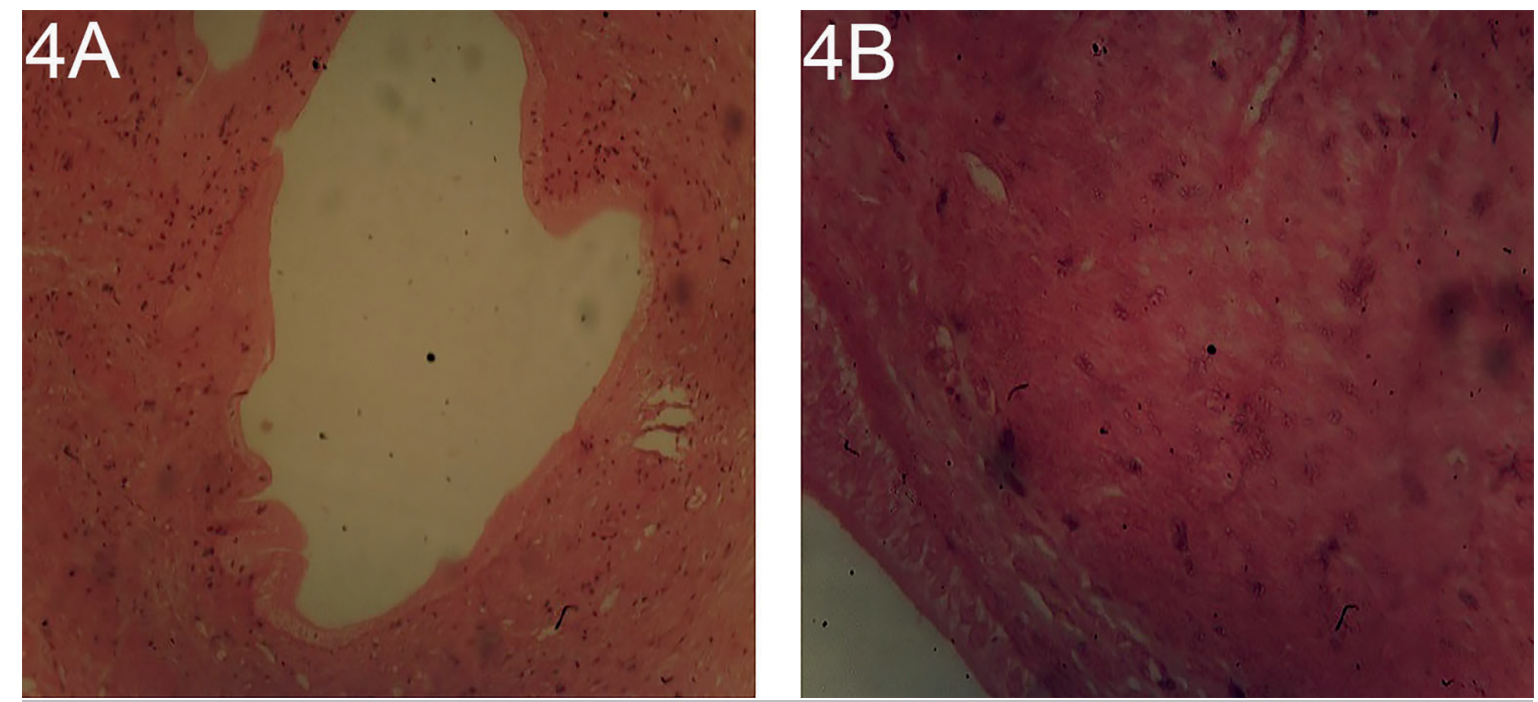

Plates 4A and B. Uterine section of rats treated with $12 \mathrm{mg} / \mathrm{kg} / \mathrm{body}$ weight of dexamethasone stain with H/E X100 and X400 Shows dilation/cystic change in endometrial glands, Neutrophil infiltration of endometrium, transformation of luminal/glandular columnar epithelium into a stratified squamous epithelium and squamous metaplasia present in luminal and glandular epithelia.
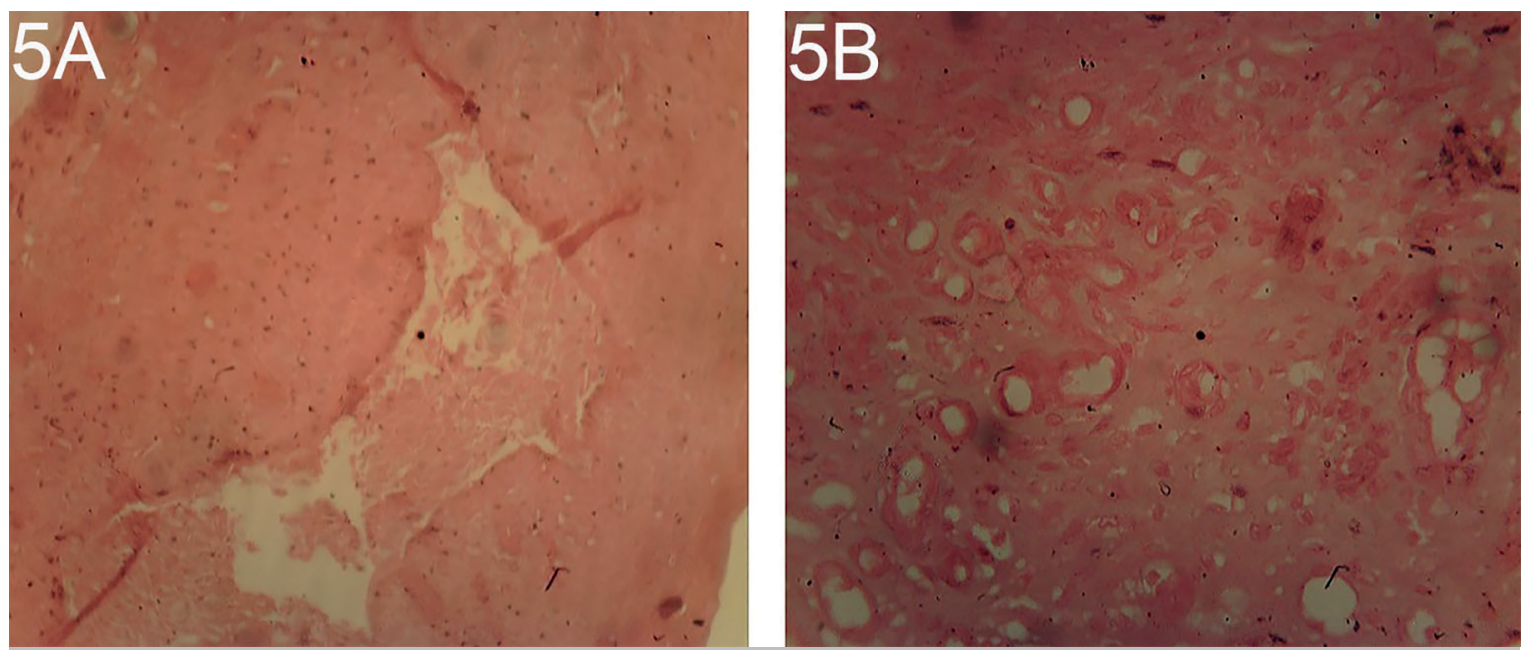

Plates 5A and B. Ovarian section of a rat treated with $10 \mathrm{mg} / \mathrm{kg} / \mathrm{body}$ weight of dexamethasone, stained with $\mathrm{H} / \mathrm{E} \times 100$ and $\mathrm{X} 400$. Atrophy inactive interstitial glands, reduced numbers of Follicles and corpora luteal, follicular cysts and stromal cell hypertrophy/hyperplasia.
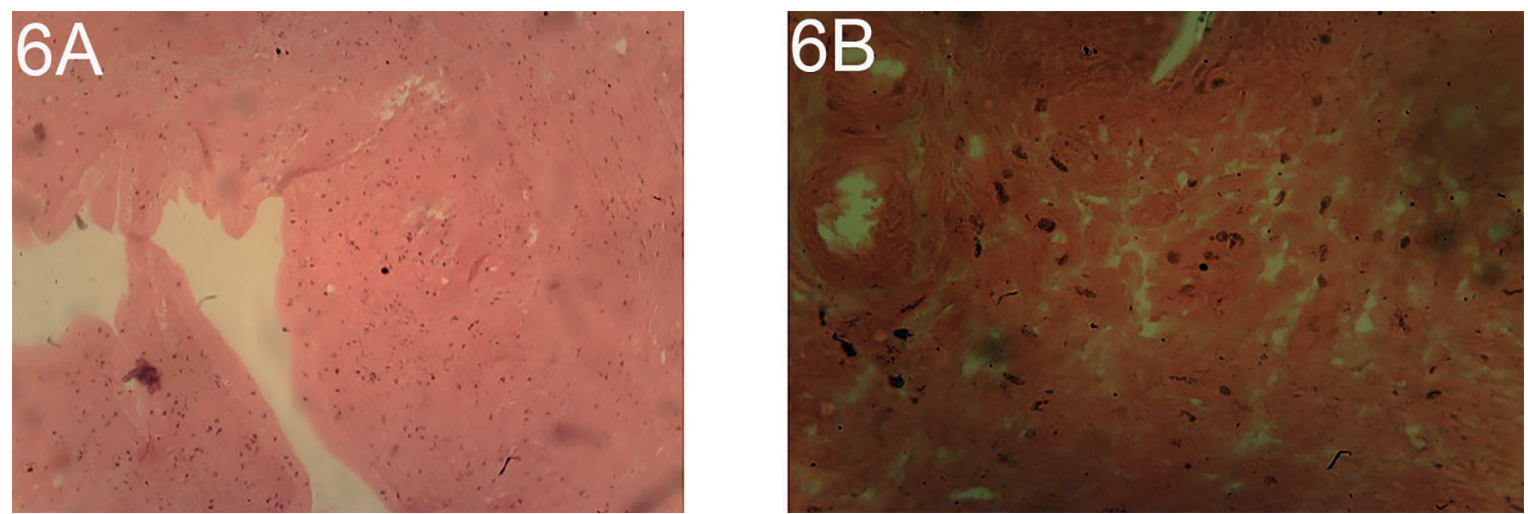

Plates 6 A and B. Ovarian session of a rat treated with $12 \mathrm{mg} / \mathrm{kg} / \mathrm{body}$ weight of dexamethasone stained with $\mathrm{H} / \mathrm{E} \times 100$ and $\mathrm{X} 400$, with atrophic inactive interstitial gland and interstitial stromal cell hypertrophy/ hyperplasia, reduced numbers of Follicles and corpora luteal and follicular cysts. 

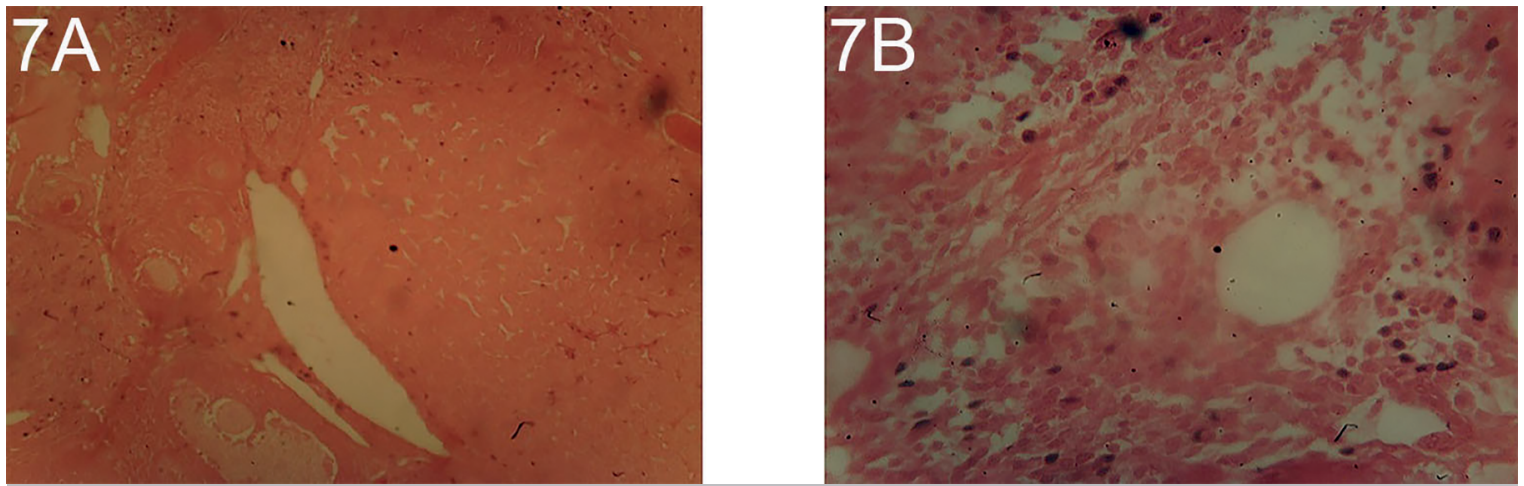

Plates 7 A and B. Ovarian section of rats treated with $7 \mathrm{mg} / \mathrm{kg} / \mathrm{body}$ weight of dexamethasone stained with H/E X100 and X400. Degenerating follicles, with oocyte cell death, Cyst (C) formation within a corpus Luteum (CL) and vacuolation of the ovarian cortex. It also shows an obvious reduction in the number of follicles and corpora luteal, this characterizes ovarian atrophy.

axis, induced the proopiomelanocortin peptide, such as $\beta$-endorphin, which reduce the hypothalamic GnRH pulse generator activity and concurrently inhibits GnRH secretion. This results in decrease pulsatile release of $\mathrm{LH}$, subsequently leading to anovulation, interruption of endometrial decidualization and pregnancy wastage (Pazirandeh et al., 2002; Kim et al., 2002).

\section{CONCLUSION}

The results of the present study indicates that the administration of high doses of dexamethasone resulted in changes to the histological features of the ovary and uteruses of adult female rats, typical of type I and type II anti-oestrogenic effects. The administration of dexamethasone resulted in decreased activities of carbohydrate enzymes of the uterus metabolism, and reduction in body weight.

\section{Recommendation}

This study has established a positive correlation in the stressor action, using a dexamethasone model and the female infertility among the adult Wistar rats. It is therefore, pertinent to extrapolate from relevant studies that will make use of human subjects, within the limits of the ethics as a model study to evaluate antifertility, promoting effects of the endocrine disruptors of which dexamethasone is part.

\section{CONFLICT OF INTEREST}

The authors declare that there is no conflict of interest.

\section{Corresponding Author:}

Joseph Babatunde Dare

Anatomy Department

Faculty of Basic Medical Sciences

College of Health Sciences

Osun State University

Osogbo, Nigeria

E-mail:babatunde.dare@uniosun.edu.ng

jdare_tolu@yahoo.com

\section{REFERENCES}

Agarwal A, Gupta S, Sharma R. Role of oxidative stress in female reproduction. Reprod Biol Endocrinol. 2005;3:28. PMID: 16018814 DOI: $10.1186 / 1477-7827-3-28$

Bloom SL, Sheffield JS, McIntire DD, Leveno KJ. Antenatal dexamethasone and decreased birth weight. Obstet Gynecol. 2001;97:485-90. PMID: 11275014 DOI: $10.1016 /$ S0029-7844(00)01206-0
Brady CJ, Villanti AC, Law HA, Rahimy E, Reddy R, Sieving PC, Garg SJ, Tang J. Corticosteroid implants for chronic non-infectious uveitis. Cochrane Database Syst Rev. 2016;2:CD010469. PMID: 26866343 DOI: 10.1002/14652969.CD010469.pub2.

Carlson NR. Physiology of Behavior. 11th ed. Boston: Allyn \& Bacon; 2010.

Charmandari E, Kino T, Ichijo T, Chrousos GP. Generalized glucocorticoid resistance: clinical aspects, molecular mechanisms, and implications of a rare genetic disorder. J Clin Endocrinol Metab. 2008;93:1563-72. PMID: 18319312 DOI: $10.1210 /$ jc. $2008-0040$

Chrousos GP, Detera-Wadleigh SD, Karl M. Syndromes of glucocorticoid resistance. Ann Intern Med. 1993;119:111324. PMID: 8239231. DOI: 10.7326/0003-4819-119-11199312010-00009

Cymerman A, Rock PB. Medical Problems in High Mountain Environments. A Handbook for Medical Officers. USARIEM-TN94-2. US Army Research Institute of Environmental Medicine Thermal and Mountain Medicine Division Technical Report; 1994 [cited 2017 Sep 12]. Available at: http://www.dtic.mil/dtic/tr/fulltext/u2/a278095.pdf

Gao HB, Tong MH, Hu YQ, You HY, Guo QS, Ge RS, Hardy MP. Mechanisms of glucocorticoid-induced Leydig cell apoptosis. Mol Cell Endocrinol. 2003;199:153-63. PMID: 12581887. DOI: $10.1016 /$ S0303-7207(02)00290-3

Goldman JM, Laws SC, Balchak SK, Cooper RL, Kavlock RJ. Endocrine-disrupting chemicals: prepubertal exposures and effects on sexual maturation and thyroid activity in the female rat. A focus on the EDSTAC recommendations. Crit Rev Toxicol. 2000;30:135-96. PMID: 10759430. DOI: 10.1080/10408440091159185.

Inoue M, Sato EF, Nishikawa M, Park AM, Kira Y, Imada I, Utsumi K. Mitochondrial generation of reactive oxygen species and its role in aerobic life. Curr Med Chem. 2003;10:2495505. PMID: 14529465 DOI: $10.2174 / 0929867033456477$

Kim HS, Shin JH, Moon HJ, Kim TS, Kang IH, Seok JH, Kim IY, Park KL, Han SY. Evaluation of the 20 day pubertal female assay in Sprague-Dawley rats treated with DES, tamoxifen, testosterone, and flutamide. Tox Sci. 2002;67:52-62. PMID: 11961216 DOI: $10.1093 /$ toxsci/67.1.52 
Klein NC, Go $\mathrm{CH}$, Cunha BA. Infections associated with steroid use. Infect Dis Clin North Am. 2001;15:423-32. PMID: 11447704 DOI: $10.1016 /$ S0891-5520(05)70154-9

Koch CA, Doppman JL, Patronas NJ, Nieman LK, Chrousos GP. Do glucocorticoids cause spinal epidural lipomatosis? When endocrinology and spinal surgery meet. Trends Endocrinol Metab. 2000;11:86-90. PMID: 10707048 DOI: $10.1016 / \mathrm{S} 1043-2760(00) 00236-8$

Leung DY, Hanifin JM, Charlesworth EN, Li JT, Bernstein IL, Berger WE, Blessing-Moore J, Fineman S, Lee FE, Nicklas RA, Spector SL. Disease management of atopic dermatitis: a practice parameter. Joint Task Force on Practice Parameters, representing the American Academy of Allergy, Asthma and Immunology, the American College of Allergy, Asthma and Immunology, and the Joint Council of Allergy, Asthma and Immunology. Work Group on Atopic Dermatitis. Ann Allergy Asthma Immunol. 1997;79:197-211. PMID: 9305225 DOI: 10.1016/S1081-1206(10)63003-7

Leung DY, Bloom JW. Update on glucocorticoid action and resistance. J Allergy Clin Immunol. 2003;111:3-22. PMID: 12532089 DOI: $10.1067 /$ mai.2003.97

Li S, Davies B. Evaluating rodent vaginal and uterine histology in toxicity studies. Birth Defects Res B Dev Reprod Toxicol. 2007;80:246-52. PMID: 17570136 DOI: $10.1002 /$ bdrb. 20120

Liu C, Guan J, Kang Y, Xiu H, Chen Y, Deng B, Liu K. Inhibition of dehydration-induced water intake by glucocorticoids is associated with activation of hypothalamic natriuretic peptide receptor-A in rat. PLoS One. 2010;5:e15607. PMID: 21187974 DOI: 10.1371/jornal.pone.0015607

Liu C, Chen Y, Kang Y, Ni Z, Xiu H, Guan J, Liu K. Glucocorticoids improve renal responsiveness to atrial natriuretic peptide by up-regulating natriuretic peptide receptor-A expression in the renal inner medullary collecting duct in decompensated heart failure. J Pharmacol Exp Ther. 2011;339:203-9. PMID: 21737535 DOI: 10.1124/jpet.111.184796

Lupien SJ, McEwen BS, Gunnar MR, Heim C. Effects of stress throughout the lifespan on the brain, behaviour and cognition. Nat Rev Neurosci. 2009;10:434-45. PMID: 19401723. DOI: $10.1038 / \mathrm{nrn} 2639$

Matsuwaki T, Suzuki M, Yamanouchi K, Nishihara M. Glucocorticoid counteracts the suppressive effect of tumor necrosis factor-alpha on the surge of luteinizing hormone secretion in rats. J Endocrinol. 2004;181:509-13. PMID: 15171698 DOI: $10.1677 /$ joe.0.1810509

Mazerbourg S, Bondy CA, Zhou J, Monget $\mathrm{P}$. The insulin-like growth factor system: a key determinant role in the growth and selection of ovarian follicles? A comparative species study. Reprod Domest Anim. 2003;38:247-58. PMID: 12887564 DOI: $10.1056 / j .1439-0531.2003 .00440 . x$

Pazirandeh A, Xue Y, Prestegaard T, Jondal M, Okret S. Effects of altered glucocorticoid sensitivity in the $T$ cell lineage on thymocyte and T cell homeostasis. FASEB J. 2002;16:7279. PMID: 11923224 DOI: 10.1096/fj.01.0891fje
Pelt AC, ed. Glucocorticoids: Effects, Action Mechanisms, and Therapeutic Uses. Hauppauge: Nova Science; 2011.

Provan D, Stasi R, Newland AC, Blanchette VS, BoltonMaggs $P$, Bussel JB, Chong BH, Cines DB, Gernsheimer TB, Godeau B, Grainger J, Greer I, Hunt BJ, Imbach PA, Lyons G, McMillan R, Rodeghiero F, Sanz MA, Tarantino M, Watson $S$, Young J, Kuter DJ. International consensus report on the investigation and management of primary immune thrombocytopenia. Blood. 2010;115:168-86. PMID: 19846889 DOI: 10.1182 /blood-2009-06-225565

Revollo JR, Cidlowski JA. Mechanisms generating diversity in glucocorticoid receptor signaling. Ann $N$ Y Acad Sci. 2009;1179:167-78. PMID: 19906239 DOI: 10.1111/j.1749-6632.2009.04986.x

Rhen T, Cidlowski JA. Antiinflammatory action of glucocorticoids-new mechanisms for old drugs. N Engl J Med. 2005;353:1711-23. PMID: 16236742 DOI: $10.1056 / \mathrm{NE}-$ JMra050541

Sheehan DC, Hrapchak BB, eds. Theory and practice of histotechnology. 2nd Edition, St Louis:The CV Mosby Company; 1980

Song JW, Park EY, Lee JG, Park YS, Kang BC, Shim YH. The effect of combining dexamethasone with ondansetron for nausea and vomiting associated with fentanyl-based intravenous patient-controlled analgesia. Anaesthesia. 2011;66:263-7. PMID: 21401538 DOI: $10.1111 / \mathrm{j} .1365-$ 2044.2011.06648.x

Sugama S, Conti B. Interleukin-18 and stress. Brain Res Rev. 2008;58:85-95. PMID: 18295340 DOI: $10.1016 / \mathrm{j}$. brainsresrev.2007.11.003

Sugino N, Karube-Harada A, Taketani T, Sakata A, Nakamura Y. Withdrawal of ovarian steroids stimulates prostaglandin F2alpha production through nuclear factor-kappaB activation via oxygen radicals in human endometrial stromal cells: potential relevance to menstruation. J Reprod Dev. 2004;50:215-25. PMID: 15118249 DOI: $10.1262 / j d r .50 .215$

Tarín JJ. Potential effects of age-associated oxidative stress on mammalian oocytes/embryos. Mol Hum Reprod. 1996;2:717-24. PMID: 9239688 DOI: 10.1093/ molehr/2.10.717

Tsigos C, Chrousos GP. Physiology of the hypothalamic-pituitary-adrenal axis in health and dysregulation in psychiatric and autoimmune disorders. Endocrinol Metab Clin North Am. 1994;23:451-66. PMID: 7805648

Yuan Y. Female reproductive system. In: Haschek WM, Rousseaux CG, eds. Handbook of Toxicologic Pathology. London: Academic Press; 1991. p. 891-935. 